EDITOR'S NOTE FOR MODULE 1: We begin publishing with two illustrations of some of the wide variety of types of articles for which PCSP is calling. These include a case study by Arnold A. Lazarus, and a case study method article by myself. Lazarus' article, which is a substantially expanded version of an earlier published therapy case, exemplifies the work of a senior clinician who practices in a clinical rather than a research context. Note that on the Instructions for Authors section of the PCSP web site, we urge authors to employ our suggested common headings where feasible. The Lazarus case article is an example that does follow these headings.

My article, which is a revised and updated version of one that appeared in 2001 in Applied and Preventive Psychology, elaborates upon the underlying rationale of PCSP's main mission: to create a scholarly database of systematic case studies for practice, research, and training purposes; and at the same time to continuously reflect upon and work to improve the methods being employed for creating the case studies.

Reader reactions and comments to both articles are enthusiastically welcomed. These should be addressed to me via the Letters to the Editor section of the web site. - Daniel B. Fishman

\title{
The Case of "Ben": A Flexible, Holistic Application of Multimodal Therapy*
}

\author{
ARNOLD A. LAZARUS ${ }^{a, b}$ \\ ${ }^{a}$ Independent practice, The Lazarus Institute, and Rutgers University. \\ ${ }^{\mathrm{b}}$ Correspondence concerning this article should be addressed to Arnold A. Lazarus, 56 Herrontown Circle, \\ Princeton, NJ, US, 08540.Email: aalaz@aol.com \\ *Note: This article is an expanded and modified version of a case that appears in a chapter I wrote in F.W. \\ Kaslow \& J.Lebow (Eds.). (2004). Comprehensive handbook of psychotherapy, volume 4, integrativeleclectic, \\ pp. 241-254. New York: John Wiley. I thank John Wiley \& Sons. Inc. for permission to republish material from \\ the original chapter.
}

\begin{abstract}
"Ben," a white, male executive who was 50 years old at the beginning of therapy, presented with anxiety, depressive mood, anger, and relationship and career problems. The case, involving therapy in a private practice setting, illustrates some of the diverse individual client needs, life complexities, and accompanying twists and turns that can emerge in treatment. While grounded in a cognitive-behavioral framework, the "Multimodal Therapy" model employed in Ben's case is designed to be responsive to such challenges by drawing procedures from other traditions, when necessary, within the framework of a "technical eclecticism." In addition, the case illustrates attempts within the multimodal model to balance science versus artistry, and planned structure vs. creativity and flexibility.
\end{abstract}

Key words: multimodal therapy; anxiety; depressive mood; anger management; couple and family problems; career problems; therapeutic flexibility; melancholia. 
The Case of "Ben": A Flexible, Holistic Application of Multimodal Therapy

\section{CASE CONTEXT AND METHOD}

\section{A) The Rationale for Selecting This Particular Client for Study}

"Ben" -- a white, male executive who was 50 years old at the beginning of therapy -- initially presented primarily with anxiety, anger, and relationship problems. The main reason for selecting "Ben" for a systematic write-up is because this case illustrates a variety of "choice points" that emerged when matters went off track. Several events derailed the ongoing therapy and called for interventions and strategies that had not been a part of the initial plan. A case study that describes a smooth monotonic progression from intake to discharge would leave the reader shortchanged when confronting the many issues that often tend to arise and call for tactical and strategic shifts and rapid revisions of the initial treatment plan.

\section{B) The Methodological Strategies Employed for Enhancing the Rigor of the Study}

It would have been far better methodologically if this case had not been taken from my routine clinical practice but had been audiotaped, or preferably videotaped, and subjected to independent assessors. Also, the services of an independent researcher to assess the client before, during and after the therapy and render an independent report would have been of enormous methodological value. While this was not feasible in the context of my routine practice (nor is it usually practicable in typical clinical settings), it should be noted that my work environment has prompted me to publish numerous case studies over the years that have evoked critical observations from a number of sources, all of which has enhanced my own critical selfawareness about my ongoing work. Also, it is my custom to present various cases to two postdoctoral groups with whom I meet regularly in Princeton and in New York, and where astute feedback helps to keep me on track. The case in point benefited from this process.

\section{C) The Clinical Setting in Which the Case Took Place}

Ben had called for an appointment shortly after reading one of my self-help books co-authored with my son, Clifford N. Lazarus (Lazarus \& Lazarus, 1997). He was feeling "down in the dumps" at the time and gravitated to the self-help section of a bookstore where he spotted The 60-Second Shrink and browsed through parts of it. He said, "It offered an approach that I did not know existed." He was seen in my professional office and paid a prearranged fee for service after each session, for which he received partial reimbursement from his insurance company.

\section{D) Sources of Data Available Concerning the Client}

With Ben's written permission, I called and discussed him with his previous therapist, who said that she had made little headway with him. She said she was trying to help him with his overall ambivalence, dependency issues, and saw him as having several features of an Avoidant Personality Disorder. She mentioned that two other therapists whom she knew quite well, both 
The Case of "Ben": A Flexible, Holistic Application of Multimodal Therapy

A.A. Lazarus

Pragmatic Case Studies in Psychotherapy, http://pcsp.libraries.rutgers.edu

Volume 1, Module 1, Article 1, pp. 1-15, 01-01-2005 [copyright by author]

women, had also been unable to make much progress with him, and opined that a male therapist might be better able to help him. Ben's history of psychotherapy went back about 20 years. He sought help from several therapists for "various crises and commitment problems." Most of the clinicians he had seen were psychodynamic, except for a Gestalt Therapist who "gave me permission to be angry," and an "existential therapist" with whom he enjoyed discussing philosophy. He stated that usually after 3-6 months he would terminate the therapy, either because he was feeling less stressed, or because the process had become circular and unhelpful. Ben mentioned that he was attracted to the cognitive-behavior therapy (CBT) orientation described in The 60-Second Shrink. (The book is a popularized version of personal change ideas that flow from the CBT model, organized as 116 "tips and strategies" to help readers handle key life issues and common mental health problems. These include how to deal with anger, depression, stress, anxiety, the vital elements of a successful marriage, and effective parenting.)

I also had Ben complete a Multimodal Life History Inventory (MLHI). This is an instrument that my son, Clifford N. Lazarus and I developed (Lazarus \& Lazarus, 1991), which includes qualitative and quantitative assessments covering the seven dimensions of psychological functioning that form the core of the "Multimodal Therapy" model that I employ. (I describe this model below in section 3, Guiding Conception.) While there are no published norms on the MLHI per se, therapists like myself who have used it with a large number of clients have developed their own clinical norms for helping to interpret a client's responses to the inventory.

Finally, I gave Ben the Beck Depression Inventory (Beck, A.T., Steer, R.A., \& Brown, G.K., 1996), both shortly after he started seeing me and at a later point in the therapy. His two scores, 11 (generally in the normal range) and 25 (generally in the depressed range), respectively, will be discussed below in section 7, Therapy Monitoring.

\section{E) Confidentiality}

Toward the end of the therapy the client was told that I was considering writing up his case for publication and he willingly signed a permission form. His name and other identifying details and places have been changed to maintain confidentiality.

\section{THE CLIENT}

Ben headed up the editorial department of a large publishing house. Twice divorced with a son and daughter in their early twenties from his first marriage, he had recently become involved with Holly, a talented advertising copywriter who worked for the same publisher. She was some eight years his junior, and had recently ended a turbulent 2-year marriage. Although Ben had been "in and out of counseling for the past 20 years," he insisted on reviewing his family of origin, his two failed marriages, and his past and present relationship with his children in considerable detail. I had endeavored to educate him as to how my therapy was similar in some ways and yet basically very different from all the others he had experienced in the past. I was able to expedite matters, to some extent, by explaining that a therapist's understanding of historical antecedents was often necessary and helpful in formulating a treatment regimen, but 
The Case of "Ben": A Flexible, Holistic Application of Multimodal Therapy

A.A. Lazarus

Pragmatic Case Studies in Psychotherapy, http://pcsp.libraries.rutgers.edu

Volume 1, Module 1, Article 1, pp. 1-15, 01-01-2005 [copyright by author]

that it was usually not beneficial to dwell on the past. I quipped that it was like driving a car while looking only in the rear view mirror. I also emphasized that for efficiency sake, through completion of a Multimodal Life History Inventory (MLHI) (Lazarus \& Lazarus, 1991) he would provide sufficient background information and help to pinpoint specific areas of his life that were troublesome.

As already mentioned, before coming to see me, Ben had received several years of insight and exploratory therapy without significant change. In line with my Guiding Conception of therapy (see below), the first step was to discuss with him the observation that therapy, when viewed as education, using social skills learning strategies rather than insight as a major method, calls for didactic methods, homework assignments, with an emphasis on "doing things differently and doing different things." He was told, for instance, that he might require training in anger management and assertive expression, and that he may be urged to take certain emotional risks (e.g., expressing his true feelings). "Sounds good to me," said he. He also expressed his positive reaction to the notion of seeing the therapist, not as a sounding board, but as a good listener and an active trainer.

\section{GUIDING CONCEPTION, WITH SUPPORT FROM RESEARCH AND CLINICAL EXPERIENCE}

As I will now underscore, the Multimodal Therapy approach that I have developed provides a framework that facilitates systematic treatment selection in a broad-based, comprehensive and yet highly focused manner. (For a detailed exposition of Multimodal Therapy and some of the research and clinical experience that underlie it, see Lazarus [1976, 1985, 1989, 2004, 2005a, 2005b]). The model respects science and data driven findings, and it endeavors when possible to use empirically supported methods (Nathan \& Gorman, 2002). Nevertheless, it recognizes that many issues still fall into the gray area in which artistry and subjective judgement are necessary, and tries to fill the void by offering methods that have strong clinical support.

By "artistry and subjective judgment," I am alluding to issues and questions that are encountered for which there are no answers from controlled research. "Should I tell my new boyfriend about the abortion I had 4 years ago?" "I wonder if I should tell my friend Clarice what her husband said about her." "Do you think I should accept that job offer in Ohio?" "I wonder whether it will help or make matters worse if I discuss what really happened at the party." Examples are almost limitless. There are those therapists who never directly answer questions but only reflect back to the client what she or he is saying. This seems to be a masterful evasion of a clinician's duty to educate, provide assistance, clarify, and illuminate options for the client. In the management of some of Ben's choices, the reader will see the precise decision-making processes that were applied.

The multimodal approach emphasizes that, at base, we are biological organisms (neurophysiological/biochemical entities) who behave (act and react); emote (experience affective responses); sense (respond to tactile, olfactory, gustatory, visual and auditory stimuli); imagine 
The Case of "Ben": A Flexible, Holistic Application of Multimodal Therapy

(conjure up sights, sounds and other events in our mind's eye); think (entertain beliefs, opinions, values and attitudes); and interact with one another (enjoy, tolerate, or suffer various interpersonal relationships). By referring to these seven discrete but interactive dimensions or modalities as

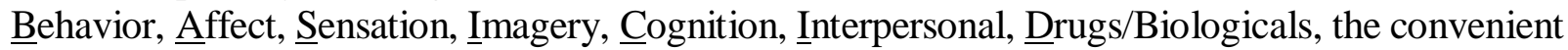
acronym "BASIC I.D." emerges.

Many psychotherapeutic approaches are trimodal, addressing affect, behavior, and cognition -- ABC. The multimodal approach provides clinicians with a comprehensive template. By separating sensations from emotions, distinguishing between images and cognitions, emphasizing both intraindividual and interpersonal behaviors, and underscoring the biological substrate, the multimodal orientation is most far-reaching. By assessing a client's BASIC I.D. one endeavors to "leave no stone unturned."

\section{Multimodal Assessment and Formulation}

The elements of a through assessment involve the following range of questions:

B: What behaviors is this individual engaging in that are getting in the way of his or her happiness of personal fulfillment (self-defeating actions, maladaptive behaviors)? What does the client need to increase and decrease? What should he/she stop doing and start doing?

A: What emotions (affective reactions) are predominant? Are we dealing with anger, anxiety, depression, combinations thereof, and to what extent (e.g., irritation versus rage; sadness versus profound melancholy)? What appears to generate these negative affects -- certain cognitions, images, interpersonal conflicts? And how does the person respond (behave) when feeling a certain way? It is important to look for interactive processes -- what impact do various behaviors have on the person's affect and vice versa? How does this influence each of the other modalities?

S: Are there specific sensory complaints (e.g., tension, chronic pain, tremors)? What feelings, thoughts and behaviors are connected to these negative sensations? What positive sensations (e.g., visual, auditory, tactile, olfactory and gustatory delights) does the person report? This includes the individual as a sensual and sexual being. When called for, the enhancement or cultivation of erotic pleasure is a viable therapeutic goal. The importance of the specific senses is often glossed over or even by-passed by many clinical approaches.

I: What fantasies and images are predominant? What is the person's "self-image?" Are there specific success or failure images? Are there negative or intrusive images (e.g., flashbacks to unhappy or traumatic experiences)? And how are these images connected to ongoing cognitions, behaviors, affective reactions, and the like?

C: Can we determine the individual's main attitudes, values, beliefs and opinions? What are this person's predominant shoulds, oughts and musts? Are there any definite dysfunctional beliefs or irrational ideas? Can we detect any untoward automatic thoughts that undermine his or her functioning? 
The Case of "Ben": A Flexible, Holistic Application of Multimodal Therapy

A.A. Lazarus

Pragmatic Case Studies in Psychotherapy, http://pcsp.libraries.rutgers.edu

Volume 1, Module 1, Article 1, pp. 1-15, 01-01-2005 [copyright by author]

I.: Interpersonally, who are the significant others in this individual's life? What does he or she want, desire, expect and receive from them, and what does he or she, in turn, give to and do for them? What relationships give him/her particular pleasures and pains?

D.: Is this person biologically healthy and health conscious? Does he or she have any medical complaints or concerns? What relevant details pertain to diet, weight, sleep, exercise, legal medications, and alcohol and illegal drug use?

The foregoing assessment methods clearly make known the client's presenting problems, the modalities involved, and the cluster of interconnected issues. These findings, often in concert with additional input and evaluation from the client, point to the goals of therapy and the methods, strategies and procedures that are most likely to help the client meet his or her goals. These methods and strategies are drawn from those that have been empirically found to work in a variety of different therapy approaches ("technical eclecticism," e.g., see Lazarus, 2005b), although all of them are conceptualized within a cognitive-behavioral framework (Lazarus, 1997, 2005a). All of this should become apparent as we discuss the initial formulation and subsequent changes of Ben's proposed treatment trajectory. The client's motivation and resilience will determine how rapidly one may proceed, the order of problems that require consideration, and the manner in which homework assignments and between-session activities can be implemented. The reader is referred to Lazarus (2005a, 2005b) for more detailed information that goes beyond the scope of the present case history.

It is important to underscore that the multimodal model does not deal specifically with shifts and revisions that can occur in therapy. The model assumes that these psychological dances and flexible maneuvers are part of the artistry and should be in the repertoire of any competent clinician. In line with this, I believe it is particularly important to document in specific cases how this artistry takes place, so that it will later be possible to inductively derive guidelines that capture the various patterns by which this artistry can be effective.

Another dimension of flexibility in my guiding conception - and one reflected in the specifics of Ben's case below -- is the assumption that while generally the therapist encourages clients to develop their own goals and life choices, so that they might fully own them, there are times when clients can make wrong choices without realizing the consequences for their mental health and well being. In my view, these instances call for the therapist to try to persuade the client to make a decision that seems in his or her best interests. This might be seen as consistent with the behavioral idea of "stimulus control," in which the therapist helps to create an environment that facilitates positive responses and consequences for the client.

A final issue contained in my guiding conception is flexibility with regard to the patienttherapist relationship. With some clients, strict and formal boundaries are necessary, whereas with others, a much more open and reciprocal relationship may ensue. There is a vast difference between "boundary crossings," which are often helpful, and "boundary violations," which are detrimental. (Examples of such boundary crossings are in-office strategic therapist self- 
disclosures, nonsexual touching, and out-of-office encounters such sharing a meal at a restaurant, attending a client's graduation, or teaching a class that a client attends. Examples of boundary violations are sexual activities with clients or obtaining "inside" stock tips from a client who is a stockbroker.) To my mind, the two major ethical concerns are the avoidance of any form of exploitation, and respect for confidentiality. But such matters as selective self-disclosure, and nonsexual dual relationships are part and parcel of the emphasis on flexibility. These issues are discussed in great detail in Lazarus and Zur (2002).

\section{ASSESSMENT OF THE CLIENT'S PRESENTING PROBLEMS AND GOALS}

At the end of the initial interview Ben was handed a copy of the Multimodal Life History Inventory (see above for a description) and asked to complete it at home and bring it with him to his second session. On the MLHI he described his problems as follows:

Restless, uptight, rarely feel fulfilled or satisfied; relationships with women don't last (I bail out) - fear intimacy; seem to have (still) lots of anger not successfully dealt with; still feel somewhat insecure (much better than before, though); fear speaking up and out.

In his other responses to the MLHI and in our sessions, Ben elaborated upon the theme that he felt "generally unappreciated" on the job, by his children, and by Holly. He reiterated his basic dissatisfactions and insecurities, his fear of intimacy and his specific relationship with Holly, his anger, and his unassertive proclivities.

The initial diagnosis appeared to be a Generalized Anxiety Disorder, although as therapy continued an Adjustment Disorder with Mixed Anxiety and Depressed Mood seemed more apt as themes of depression and situational stress also surfaced. He attributed many of his problems to the fact that he felt "displaced" having been an only child for four years, after which his mother gave birth to another three sons in close succession.

\section{FORMULATION AND TREATMENT PLAN}

Based on my initial assessment, and in line with the research and clinical literature and my prior experiences with similar cases, at first it seemed that the treatment plan would follow the well-researched pathway of cognitive-behavior therapy in which each of Ben's significant problems would be addressed, wherever feasible, by an empirically supported method and in an appropriate and suitable solution-focused manner (e.g., Nathan \& Gorman, 2002). Consequently, a standard series of cognitive-behavioral procedures was embarked on - relaxation training (for his overall tension and anxiety); role playing (to acquire a better way of discussing matters at work and with Holly); cognitive restructuring (Ben was apt to have too many "shoulds" and selfdowning cognitions); and assertiveness training (to deal appropriately rather than evasively with his children, with Holly, and to be able to express his anger nonaggressively). This course of therapy flowed naturally from my guiding conception that initiating specific cognitive-behavioral procedures was the best way to deal with the type of problems with which Ben presented. 
As mentioned earlier, my guiding conception stipulates that the speed at which one may proceed, the order of problems that call for attention, and the level at which homework assignments and between-session activities can be implemented depend largely on the client's motivation and resilience. In line with the above, initially it seemed advisable to divide session time among methods of "cognitive restructuring" (in which his faulty cognitions would be replaced by adaptive thoughts and valid perceptions) and various forms of role-playing to contain his irrational anger, enhance specific social skills, and encourage assertive expression. At this juncture it was anticipated that a 5 or 6 -session trajectory would be sufficient. By the third session it was necessary to put the plan on hold.

In general, it is not uncommon to find therapists who continue with their initial plans even when they should be deferred. They often assume that if the initial objectives are achieved, other matters may fall into place. If not, these other tribulations can then be examined and treated. Usually, the failure to be sufficiently flexible, to ignore and disrespect the client's priorities, can derail the relationship. The inability to recognize when preemptive adjustments in the treatment plan are called for may totally undermine the therapy. Some therapists have argued that they must demonstrate who is in charge and not permit the client to take control. From the perspective of my guiding conception, this type of dismissal is viewed as only leading the client to feel unheard, disrespected, and misunderstood.

\section{COURSE OF THERAPY}

During the first three sessions I managed to apply some "cognitive restructuring" in which I pointed out Ben's proclivity to think dichotomously and his penchant to denigrate himself, especially when discussing past mistakes. Most of these sessions, as previously mentioned, were devoted to his recounting his family background - my active listening at this stage seemed to be a necessary rapport-building process. Nevertheless, in addition to identifying his faulty cognitions, I also managed to do some role-playing to contain his irrational anger and encourage assertive expression. For example, when he dwelled on some strong resentment to various family members because of what he considered their unfair treatment of him, I invited him to try out a role-playing scenario. I would model some assertive comments, and he could "try them on for size." He complied, saying, "I guess this will enable me to put up with less of their crap in the future."

By the end of the third session it became clear to me that several significant events called for the treatment plan's deferral. Ben and Holly kept on ending and resuming their relationship, which precipitated various crises. Consequently, I tabled the individual cognitive-behavior therapy (CBT) approach and paid exclusive attention to their relationship. I began seeing Ben and Holly regularly for CBT-oriented couples counseling (e.g., Lazarus, 2001). A clear pattern emerged. Ben and Holly had specific points of disagreement, and when any one of these came into play, Ben would go on the attack and Holly would withdraw but retaliate passiveaggressively. Here again I selected role-playing as a viable means for promoting rational 
The Case of "Ben": A Flexible, Holistic Application of Multimodal Therapy

A.A. Lazarus

Pragmatic Case Studies in Psychotherapy, http://pcsp.libraries.rutgers.edu

Volume 1, Module 1, Article 1, pp. 1-15, 01-01-2005 [copyright by author]

discourse. I also used the standard CBT procedure wherein a comment would be made or a request would be stated, and the listener would then seek clarification. For example:

Ben: "You are saying that I am too critical and that I never do anything around the house." Holly: "No, I didn't say that. You do a lot to keep the yard up, but you seldom help me with stuff inside the house."

Ben: "Oh. You'd like more help with stuff like the dishes?"

Holly: "Right."

Ben: "Fair enough."

These sessions enabled Ben and Holly to reach various points of agreement so that their relationship became less contentious.

After 11 months of therapy, Ben, rather impulsively, in my clinical opinion, quit his job and decided to become a freelance journalist. Ben's own framing of this was that "office politics" were wearing him down, that the job was basically a "dead end," and that "freedom" might inspire him to do some really creative writing. This too required considerable therapeutic attention. It took a few months for him to realize that his income would continue to be drastically diminished. I regarded his avoidance of committed employment as part of his irrational, "I can't stand it" proclamations. I agreed that he might not like it, but stressed that he needed the money, and was able to withstand the demands. As mentioned above in section 3, Guiding Conception, this was an instance in which I decided to take a stand for what I strongly viewed as in the client's best interest. I was quite outspoken about my view that a structured milieu would be far better than freelancing, and I encouraged him to find a job with a different publisher. He also continued to search for additional sources of income from freelance journalism.

The unexpected demise of his mother further derailed the initial treatment trajectory. We embarked on a necessary course of grief counseling. In multimodal vernacular, the Interpersonal Modality took precedence. His desires to vent his feelings, reminisce about his mother, and relate aspects of their relationship to other issues and problems were respected (e.g., he decided that his choice of women was predicated on his desire to find someone very much like his motherminus her bad points). He discussed his feelings toward his brothers and the way the Big Brother role had been foisted on him. He also became intent on drawing up "balance sheets" comparing his late mother's pros and cons with those of Holly. It became obvious that Ben was no candidate for brief psychotherapy.

A year after our initial interview, I did some "stock taking." Although he had weathered the various crises alluded to above - the ups and downs in his relationship with Holly, his job changes, and the death of his mother -- he had not made much headway in resolving many of his presenting problems, such as his level of anxiety, his penchant for unassertiveness, conflictual relationships, and dysfunctional cognitions. Consequently, we embarked once again on a series of standard cognitive-behavior therapy tactics. Relaxation methods, assertiveness training, and the implementation of several mental imagery methods that revolved around pictures wherein he perceived himself able to cope with various adversities all proved helpful. After some10 - 12 sessions of individual CBT procedures, he appeared to be less angry and resentful (which Holly 
The Case of "Ben": A Flexible, Holistic Application of Multimodal Therapy

A.A. Lazarus

Pragmatic Case Studies in Psychotherapy, http://pcsp.libraries.rutgers.edu

Volume 1, Module 1, Article 1, pp. 1-15, 01-01-2005 [copyright by author]

confirmed), he reported feeling more secure and self-accepting, and he was somewhat happier about his relationship with his children. Nevertheless, he was using alcohol to excess (he had started having at least three glasses of wine with dinner every evening), and his relationship with his children remained strained (he avoided calling them and Holly said that although he had stopped bring critical of them he complained that he felt uptight around them).

\section{THERAPY MONITORING AND THE USE OF FEEDBACK INFORMATION}

After about 15 months of therapy, Ben and I systematically discussed the gains that had accrued and the areas that now required specific attention. I asked him to take home a copy of the Multimodal Life History Inventory he had completed when we first met and to indicate thereon (a) issues and areas that had been successfully treated; (b) those that still needed to be modified; and (c) any new problems that had arisen. When he returned a week later for his next session, we perused the MLHI. It became clear that his main problem at this point was his disenchantment with his work. For example, he felt that editing and critiquing other peoples' work prevented him from fulfilling his own literary ambitions. In line with the BASIC I.D. model discussed in section 3, Guiding Conception, we then focused on the following questions: What behaviors might diminish his current work pressures? How might he generate positive feelings about his work? What sensory pleasures might be tapped into to offset his tensions? What mental images came to mind when picturing a highly satisfying work environment? In thinking through a balance sheet of pros and cons, which items stood out most clearly? What steps could be taken to counteract some of the aversive encounters he reported? From a health standpoint, was he getting sufficient rest to maximize his performance level?

These inquiries opened up a sequence of events pertaining to certain childhood and adolescent memories that seemed pertinent. For example, he felt that he had been victimized by strict and highly critical teachers, often bullied by older children, given insufficient parental guidance or help, and left to flounder through life. He concluded that these formative experiences resulted in his feeling needlessly hypervigilant and played directly into his generalized anxiety and avoidance responses.

Ben also concluded that he had not grieved sufficiently for his mother. Regarding Holly, he stated that despite her many positive attributes, she was too hypersensitive, too critical, and less accepting than he desired -- he termed her "a quintessential nit-picker."

Concerning unresolved feelings about the loss of his mother, I urged Ben to join a selfhelp support group in the community that dealt with loss and grief. Somewhat reluctantly, he followed through and attended a weekly group that was held at a local church. He went to about 6 or 7 meetings and said they had been "fairly helpful." When I recommended further couples counseling, Ben said he'd think about it.

I also suggested that a few sessions with Ben and his children might prove useful to deal with his feelings. He agreed, and Ben and I met with his adult son and daughter on two occasions 
The Case of "Ben": A Flexible, Holistic Application of Multimodal Therapy

A.A. Lazarus

Pragmatic Case Studies in Psychotherapy, http://pcsp.libraries.rutgers.edu

Volume 1, Module 1, Article 1, pp. 1-15, 01-01-2005 [copyright by author]

and then, at her request, Holly joined us for a third family session. These meetings proved effective in clearing up several misunderstandings and misperceptions. I carefully commenced these family sessions by emphasizing that as a clinical psychologist, I do not take sides but endeavor to be of genuine help to all the members of a family. I set the agenda by saying that the goal of getting together was to come up with and implement a plan that would result in a constructive and satisfying solution for all. My main consideration was understanding exactly what had caused problems in the past and what was preventing family members from having a close and caring relationship in the present. The meetings gave them all an opportunity (a) to vent their feelings, (b) make some necessary apologies, (c) clarify misunderstandings, and (d) express their mutual feelings of love for one another.

Subsequently, Ben's first wife (the mother of his children, who lived too far away to have been included in the family process) called me to say that she was pleased to report that her son and daughter had overcome needless resentments towards their father. But she urged me to impress upon Ben that parenting is a two-way street and that he should make overtures to the children from time to time rather than always waiting for them to contact him. I promised to convey this message and Ben was receptive to it. (Since I had not obtained Ben's specific permission to speak to his first wife, I structured my role in the conversation as merely a listener and a conveyer of her message.)

It was now almost 2 years since Ben had first consulted me and he reported that despite considerable progress that had been made on several fronts, he had been feeling "down." Further inquiry revealed signs of a clinical depression, a significant problem that had eluded all previous avenues of inquiry. Although from time to time Ben had said that he was feeling "depressed," he presented his frame of mind in terms of "normal ups and downs." Indeed, his reason for reading the book (Lazarus \& Lazarus, 1997) that had led him to call me, was that he had purchased it at a time when he was "down in the dumps." I had tried to delve into the nature of his dysphoria several times over the course of the therapy, but he always brushed it aside as "no big deal." At this juncture, perhaps because so many other issues had been resolved, he put a very different spin on his melancholia, and this became the focus of some 3 or 4 sessions while we tried to ascertain the forces and factors that were responsible for it. One can always discern possible psychogenic "reasons" behind dysphoric affect, but given Ben's family history (a father who had received ECT, and a mother who was clinically depressed most of her life), the most parsimonious diagnosis was that of a biologically based depression.

It should be noted that when dealing with a biological depression, a multimodal therapist does not lose sight of the fact that in addition to antidepressants or other medical treatments, certain behaviors can prove helpful (e.g., exercising and keeping active), as can sensory responses such as pleasing music and tactile pleasures, as well as positive images, self-affirming cognitions, and various interpersonal activities. Thus, in addition to recommending medication for Ben, as described below, I also employed a number of these modalities, such as persuading him to join a gym and work out with a personal trainer (behavior), to have full body massages twice a week -- which Ben had suggested himself (sensation), and to spend time with congenial friends, with or without Holly (interpersonal). 
Ben then mentioned that he had suffered similar bouts of depression. He said that he had dealt with these events by "toughing them out," although on one occasion he saw a psychiatrist who prescribed medication that made him worse. (He could not recall the name of the drug but it was clear that this experience had made him suspicious of psychiatric medication, which was mainly why he kept downplaying and denying the true degree of his depression.) I had given him the Beck Depression Inventory (Beck, A.T., Steer, R.A., \& Brown, G.K., 1996) shortly after he started seeing me and his score was only 11, which indicated a mild mood disturbance at worst. At this juncture I asked him to fill out the Beck Depression Inventory again. He scored 25, indicating a significant depression. It is my belief that he was "faking healthy" the first time. I think he did so for two reasons. (1) He did not want to appear too needy for fear that I may not accept him as a client. (2) He also probably did not want to admit to the full extent of his problems himself. When I first said that I would like him to see a psychopharmacologist he refused, and it took considerable persuasion before he believed that several of the new medications on the market have minimal side effects. He saw the person I had recommended who prescribed Effexor. It proved helpful, with minimal side-effects, and Ben took this medication for over a year.

Holly entered into therapy with a female psychologist who requested to see Ben. I had not been contacted or asked to have any input in this. I felt that it was probably best for Holly and Ben to do this on their own. My rationale for staying out of it was so as not to be seen as too controlling, or perhaps as needlessly defensive or territorial. Ben saw the therapist alone and then together with Holly for a few sessions. Ben had feared that Holly and her therapist would gang up on him, but he reported to the contrary, that Holly had been mildly rebuked for her unrealistic expectations. Ben reported, "Things between Holly and me are much better these days." He and Holly bought a house and moved in together. Up to this point they had separate abodes, although Ben had spent most of his time in Holly's house. "I just love this house we bought," Ben reported. "Just being in that home, looking out into the magnificent garden, gives me a natural high. It's even better than Effexor!"

\section{CONCLUDING EVALUATION OF THE THERAPY'S PROCESS AND OUTCOME}

At this point, about 2 years and 2 months had elapsed since Ben and I first met. Initially, during most of his first year in therapy, I had seen him on a weekly (sometimes twice weekly) basis. Our visits were now spaced at 10 day to 2-week intervals, except when certain crises had emerged when we would meet as often as needed. Over the previous six months we had met on an average of every 3-4 weeks. Ben suggested that we might now consider meeting only if and when needed. I agreed. He emphasized that we had achieved most of our goals: (a) he felt more secure; (b) his anger had diminished significantly; (c) he was inclined to assert his feelings; (d) he was pleased with his children; (e) his work situation was satisfactory; (f) he had come to terms with his mother's death; (g) he was no longer abusing alcohol; and (h) he was not feeling depressed. 
Two months later Ben made an appointment. Holly had changed jobs and was now commuting to work over 2 hours each day. Their relationship had become strained. One of his cousins with whom he was very close had died unexpectedly. "I was tapering off the medication, but I hit a down," he said, "and now I am back on a time release Effexor and take $225 \mathrm{mg}$ at night. I am also taking Buspar." We had five additional weekly sessions devoted mainly to the exploration of his relationship with Holly. Ben and Holly were both questioning the viability of their relationship. The three of us drew up individual "balance sheets" as to the pros and cons of their staying together or going their own ways. When we compared notes, it seemed that we all found too many differences (especially concerning their respective expectations of a relationship) and too much resentment. We discussed these issues and agreed that they made it unlikely that Ben and Holly could sustain a loving and non-contentious relationship.

Ben then sent me the following email: "It is crystal clear that Holly and I cannot make it. To be perfectly honest, living with her has been tepid at best. So guess what? She has decided to move into New York and I will buy her share of the house." I sent back an email inquiring if this implied that he and Holly would now definitely be separating and going their separate ways. He wrote back that nothing definite has been decided, but it was certainly heading in that direction.

Several months later, again on email, the following note arrived:

It is now fait accompli. Holly is in New York. I have bought the house - and I love it more than ever. But the best news of all is that I am seeing a woman I dated before I married my first wife. Did I ever mention Jean to you? I was nuts about her back then, but unfortunately for me, her childhood sweetheart appeared on the scene and they got married. A friend mentioned that she was divorced and living in this area. I called her, got together a few times, and things really clicked. I may want to set up an appointment so that Jean and I can discuss the pros and cons of her moving into my house with a view to getting married by the end of the year.

\section{Post Termination Synopsis and Reflections}

Instead of a formal appointment, Ben and I exchanged more emails. Five months later I received a wedding invitation and met Jean for the first time at the reception. As mentioned in section 3, the Guiding Conception behind Multimodal Therapy, this approach is very flexible when it comes to selective extra-therapeutic activities with certain clients. There was no reason to turn down Ben's wedding invitation. At a suitable moment, I took Ben aside and said, "I think you've hit the jackpot!" Subsequently, Ben and Jean met with me to discuss minor problems between her adult daughter and Ben's son and a daughter. As I write this, it is now almost 4 years since they got married. We have kept in touch via email and on a few occasions I have met Ben for lunch. Again, I want to emphasize the benefits that can accrue from certain "dual relationships," and with some clients, an expanded therapist role can have a positive effect. Ben stated that it meant a great deal to him to meet up with me more informally in a luncheon setting. These meetings have not been tantamount to free therapy. Ben and I have reacted like two friends catching up on one another's lives. In my view, this change in my role helped to solidify 
The Case of "Ben": A Flexible, Holistic Application of Multimodal Therapy

A.A. Lazarus

Pragmatic Case Studies in Psychotherapy, http://pcsp.libraries.rutgers.edu

Volume 1, Module 1, Article 1, pp. 1-15, 01-01-2005 [copyright by author]

Ben's image of himself as a successful human being rather than just as a perpetual "therapy patient." He has described himself as "happier than I ever thought I could or would be."

In thinking back over the treatment trajectory with Ben it had the quality of a proverbial roller coaster. This case illustrates the importance of flexibility, a willingness to shift gears and change direction, and the value of a broad-based CBT approach. The client received standard, individual cognitive-behavior therapy to begin with. The use of empirically supported methods is a first choice whenever clients' problems lend themselves to specific and well-established interventions. Nevertheless, this initial treatment plan was soon changed to cognitive-behavioral couples therapy, given that dyadic issues had come to the fore with the prominence of the conflict between Ben and Holly. While Ben's attitudes, feelings, and strategies with Holly could have been dealt with in individual therapy, moving to a couple's model allowed for a more direct dealing with the interactive and transactional components of their problems. The theme throughout this case study is that a clinician must always be ready to address unexpected events. The death of the client's mother also called for immediate changes in the treatment protocol.

The resumption of individual cognitive-behavior therapy for Ben's initial presenting problems then proved effective, but it was also necessary to reassess Ben's range of problems to shed further light on issues that needed to be considered and treated. Thus, family therapy sessions were deemed advisable and the client was seen together with his children, again viewed as preferable to dealing with these issues only in Ben's individual therapy. Note how the focus swung back and forth between Ben and his personalistic issues to the broader interpersonal context. The use of extra-therapeutic resources is also demonstrated by the fact that he was encouraged to join a self-help, grief-counseling group, and a referral was made to a psychopharmacologist. Ben seemed to derive benefit from the self-help group, and he certainly benefited from seeing the psychopharmacologist. He said that the grief counseling assuaged his sense of isolation and helped him put the loss of his mother into a realistic perspective. And the medication that had been prescribed for his depression was extremely helpful.

I selected this case not because it is especially noteworthy or filled with pristine insights, but because it exemplifies an analogy I use quite often - that of the therapist acting like a heatseeking missile that pursues problem after problem as they arise in real time and blows them out of the sky. As mentioned above, in Ben's case, this involved multiple modes of individual, couples, and family therapy together with the use of outside resources and moving at the end from a more formal therapist role to one of a type of friend. Moreover, the therapy had to be responsive to important changes taking place in the client's life, such as the potentially harmful alterations in his job situation, the death of his mother, the ups and downs of his relationship with Holly, and the fortunate timing of his meeting with Jean. Over the years, Ben has referred several relatives, friends and associates to me for therapy. They all reported that he had told them that I had succeeded in turning his life around.

During the $2 \frac{1}{2}$ years that I saw Ben (and the 4 years I followed him after therapy), I was the one consistent, supportive figure in his life as he grappled with an unhappy work situation, a stormy relationship with Holly, the loss of his mother, and his ungrateful kids. (Ben's father had 
The Case of "Ben": A Flexible, Holistic Application of Multimodal Therapy

died from a heart attack at age 69 a few years before Ben consulted me. His relationship with his father was basically good, and the only untoward remarks he made about him were: "As much as I liked him, I think he wanted me to be certain things and behave in certain ways that weren't me." We had discussed this a few times but it did not seem that these issues were especially relevant to the case.) My encouraging relationship with Ben was designed to provide stability, strength, and self-acceptance, while providing encouragement for him to take new directions to address the unhappy parts of his life. My attending his wedding reception and continuing to see him occasionally during the 4 years of his marriage to Jean also provided continuity with his past and the message that I cared about him as a human being, not just an "office client."

\section{REFERENCES}

Beck, A.T., Steer, R.A., \& Brown, G.K. (1996). Beck Depression Inventory -- Second Editon: Manual. San Antonio, TX: The Psychological Corporation.

Lazarus, A.A. (1976). Multimodal behavior therapy. New York: Springer.

Lazarus, A.A. (Ed.). ( 1985). Casebook of multimodal therapy. New York: Guilford.

Lazarus, A.A. (1989). The practice of multimodal therapy: Systematic, comprehensive, and effective psychotherapy. Baltimore, MD: Johns Hopkins University Press.

Lazarus, A. A. (1997). Brief but comprehensive psychotherapy: The multimodal way. New York: Springer

Lazarus, A.A. (2001). Marital myths revisited: A fresh look at two dozen mistaken beliefs about marriage. Atascadero, CA: Impact Publishers.

Lazarus, A.A. (2004). The multimodal assessment therapy approach. In F.W. Kaslow \& J.Lebow (Eds.). (2004). Comprehensive handbook of psychotherapy, volume 4, integrativeleclectic, pp. 241-254. New York: John Wiley.

Lazarus, A. A. (2005a) Multimodal therapy In R.J. Corsini, \& D. Wedding (Eds.). Current psychotherapies. (7th ed.). (Pp. 337-371). Belmont, CA: Brooks Cole.

Lazarus, A. A. (2005b). Multimodal therapy. In Norcross, J. C., \& Goldfried, M. R. (Eds.). (2005). Handbook of psychotherapy integration (2nd ed.). New York: Oxford University Press.

Lazarus, A. A., \& Lazarus, C. N. (1991) The Multimodal Life History Inventory. Champaign, IL: Research Press.

Lazarus, A. A., \& Lazarus, C. N. (1997). The 60-second shrink: 101 strategies for staying sane in a crazy world. Atascadero, CA: Impact Publishers.

Lazarus, A. A., \& Zur, O. (Eds.) (2002). Dual relationships and psychotherapy. New York: Springer.

Nathan, P.E., Gorman, J.M. (2002). A Guide to Treatments That Work, $2^{\text {nd }}$ ed. New York: Oxford University Press. 